Rev. Fac. Ing. - Univ. Tarapacá, vol. 14 Nº 1, 2006, pp. 90-94

\title{
EVALUATION OF ACCELERATION OF ATMOSPHERIC ELECTRONS DUE TO HIGH POWER HF TRANSMISSION TO EARTH IONOSPHERE
}

\section{EVALUACIÓN DE LA ACELERACIÓN DE ELECTRONES DE LAATMÓSFERA DEBIDO A TRANSMISIÓ N HACIA LA IONOSFERA TERRESTRE DE HF DE ALTA POTENCIA}

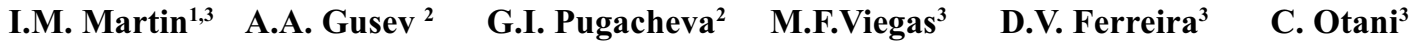 \\ Recibido el 1 de abril de 2005, Aceptado el 19 de octubre de 2005 \\ Received: April 1, 2005 Accepted: October 19, 2005
}

\begin{abstract}
RESUMEN
Es posible que, países meridionales del hemisferio, desarrollen juntos un programa científico dirigido a estudiar las propiedades y el comportamiento de la ionosfera, basado en la radiación de alta potencia de HF transmitida desde la tierra. El objetivo de este trabajo es avanzar en el conocimiento de las propiedades físicas y eléctricas del plasma de la ionosfera de la Tierra, que puede afectar principalmente a los sistemas de comunicación, navegación y cambio climático. Se describen las instalaciones de los instrumentos necesarios para la investigación en el hemisferio sur y también los cálculos del plasma para la Antártica (EACF). Los elementos principales para investigar la ionosfera consisten en un poderoso sistema transmisor de HF, que puede usarse temporalmente para excitar un área limitada de la ionosfera para los estudios científicos. La pregunta es: ¿cuál es la mayor energía alcanzada por electrones de la ionosfera acelerados por radiación electromagnética de un poderoso transmisor de HF?
\end{abstract}

Palabras clave: Física del plasma, electrones de ionosfera, transmisor de alta frecuencia, antenas, campos electromagnéticos.

\section{ABSTRACT}

It should be possible, for countries in the southern hemisphere, to develop a joint scientific program aimed at studying the properties and behavior of the Earth's ionosphere, based on terrestrial HF power transmitted radiation. The goal of this work is to further acquire knowledge about the physical and electrical properties of the Earth's ionosphere (plasma), which are of particular importance, since they can affect communication and navigation systems and climate changes. Required research instruments for the southern hemisphere measurements and also plasma calculations for Antarctica (EACF) are described. The main facilities research apparatus consists of a high power HF transmitter that can be used to temporarily excite a limited area of the Earth's ionosphere for scientific studies. The question addressed in this work is: What is the maximum energy attained by ionosphere electrons accelerated by electromagnetic wave radiation from a ground based high power HF transmitter?

Keywords: Plasma physics, ionosphere electrons, HF transmitter, antennas, electromagnetic fields.

\section{INTRODUCTION}

In an area near the polar circle of the southern hemisphere, it would be possible to install powerful high frequency (HF) transmitters. These transmitters enable the study of the properties and behavior of the ionosphere (plasma), which is of interest as it can be applied to the

1 UNITAU, Universidade de Taubaté, SP, Brazil.

2 INPE, Instituto Nacional de Pesquisas Espaciais, Santa Maria, Brazil.

3 ITA, Instituto Tecnológico de Aeronáutica, São José dos Campos, Brazil. enhancement of communications and surveillance systems.

The main scientific instrument of the complex would be the ionosphere research instrument (IRI), a powerful phased transmitter which would be installed on the ground and transmit a narrowly directed beam of radio pulses in the HF frequency range $(1-10 \mathrm{MHz})$. The IRI 
is used to temporarily excite a limited area of the ionosphere for scientific study. A general sketch of HF electromagnetic waves propagation is shown in Figure 1. The HF emission energy is transferred in situ to the electrons and ions of the cold ionosphere plasma. The powerful electromagnetic pulse affects the ionosphere charged particles in such a way that a particular volume of them is heated (locally). According to the power transmitted, the electromagnetic emissions increase the mean charged particle energy until ambient neutral atoms are ionized and a local "plasmoid" is created. The plasmoid has a higher free ion density than the natural environment.

\section{TRANSMITTER PARAMETERS}

Let us consider the case of a transmitter HF experiment PlasmaAn (Plasma Antarctica Experiment). The geographic coordinates of the EACF are $62.05^{\circ} \mathrm{S}$; $58.23^{\circ} \mathrm{W}$ at sea level, and the geomagnetic McIlvain coordinates are $L=2.29 B=0.5$ Gauss. PlasmaAn is a phased transmitter with narrowly directed $\mathrm{HF}$ radio pulse beams of high power in the frequency range of 2.8-10 $M H z$. The whole instrument consists of 360 transmitters, each with a transmission power of $10 \mathrm{~kW}$, and thus the whole instrument has a total transmitting power of 3.6 $M W$. The beam is transmitted for $30 \mathrm{sec}$, followed by an interval of $30 \mathrm{sec}$, throughout a period of 3 hours.

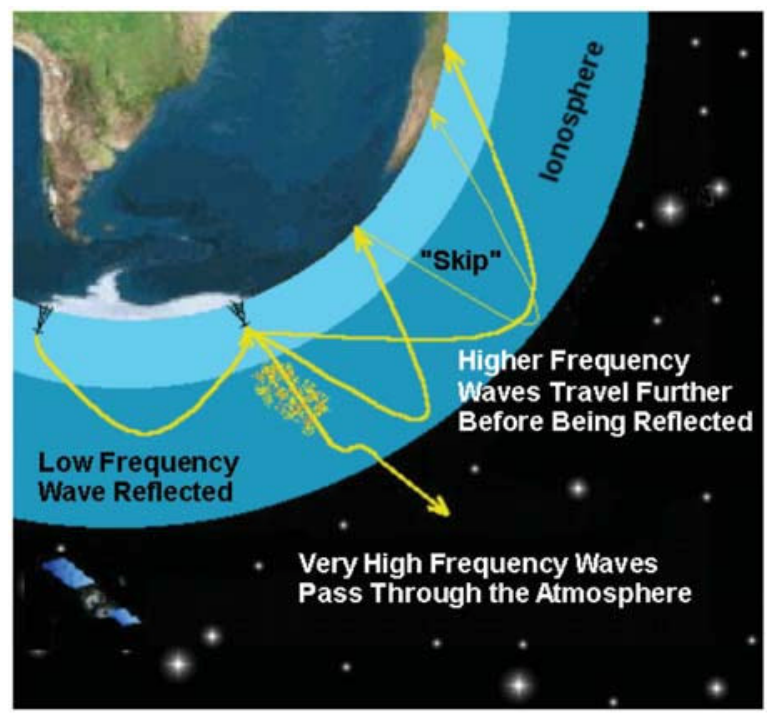

Fig. 1 View of plasmoid volume.

A transmitted beam of electromagnetic waves passes through the atmosphere practically without absorption. It begins to lose energy at altitudes of $70-250 \mathrm{~km}$ (the altitude depends on the pulse frequency), accelerating free ionosphere electrons in a volume of about 30000 $\mathrm{km}^{3}\left(20 \times 20 \times 80 \mathrm{~km}^{3}\right)$, i.e. a volume several tens of $\mathrm{km}$ in diameter and about $80 \mathrm{~km}$ in thickness, located directly over the antenna in the ionosphere. The beam of HF emission incident on the ionosphere has a power density lower than $3 \mu \mathrm{W} / \mathrm{cm}^{2}$ with an initial transmitting power of $3.6 \mathrm{MW}$, which is understandable given the large area of the ionosphere exposed to radiation $\left(20 \times 20 \mathrm{~km}^{2}\right)$. The volume between 70 and $250 \mathrm{~km}$ above the antenna is heated. Its cooling continues from several seconds up to 10 minutes after the HF antenna has been switched off.

HF emission itself affects only charged particles at these ionosphere altitudes and does not directly ionize neutral atoms there, at least at the power noted above, in spite of their density being about $3.6 \cdot 10^{13} \mathrm{at}^{\mathrm{c}} \mathrm{cm}^{3}$, i.e. $1.8 \cdot 10^{7}$ times greater than the density of free electrons $\left(2 \cdot 10^{5}\right.$ per $\mathrm{cm}^{3}$ at the same altitude of $100 \mathrm{~km}$ ). The power that causes electron and ion heating results in an extreme increase of the local temperature and the energy of the free electrons.

Let us estimate the additional energy gained by cold ionosphere electrons as a result of HF radiation with the full power of the antenna 3.6 $\mathrm{MW}$ at two frequencies 3.8 $\mathrm{MHz}$ and $9.8 \mathrm{MHz}$. The power of the incident beam at the certain altitudes and an area exposed are given in Table 1 below.

Table 1 Incident HF Power.

\begin{tabular}{|l|c|c|}
\hline \multicolumn{3}{|c|}{ HF=3.8 $\mathbf{M H z}$} \\
\hline Altitude, $\mathrm{km}$ & Area, $\mathrm{km}^{2}$ & Incident Power, $\mu \mathrm{Wl} \mathrm{cm}^{2}$ \\
\hline 100 & $26 \times 21$ & 0.47 \\
\hline 200 & $52 \times 41$ & 0.12 \\
\hline 300 & $79 \times 62$ & 0.052 \\
\hline 400 & $105 \times 82$ & 0.029 \\
\hline \multicolumn{3}{|c|}{$\mathbf{H F}=\mathbf{9 . 8} \mathbf{M H z}$} \\
\hline Altitude, $\mathrm{km}$ & Area, $\mathrm{km}^{2}$ & Incident Power, $\mu \mathrm{Wl} \mathrm{cm}^{2}$ \\
\hline 100 & $10 \times 8$ & 3.5 \\
\hline 200 & $20 \times 16$ & 0.87 \\
\hline 300 & $30 \times 24$ & 0.39 \\
\hline 400 & $41 \times 32$ & 0.22 \\
\hline
\end{tabular}

\section{ROUGH ESTIMATES OF ELECTRON HEATING}

As shown in Table 1, the power of radio emission decreases with the exponent of $84 \mathrm{~km}$. Thus the HF radiation at a frequency of $9.8 \mathrm{MHz}$ gives an energy of about $30 \times 2.2 \cdot 10^{-6} \times 10^{6} / 84 \cdot 10^{5}=7.86 \cdot 10^{-6}$ Joule per $\mathrm{m}^{3}$ during 1 pulse, i.e. the mean energy lost during 1 minute is $3.9 \cdot 10^{-6}$ Joule $\mathrm{m}^{-3}$ at an altitude of $100 \mathrm{~km}$. 
The HF radiation at a frequency of $3.8 \mathrm{MHz}$ gives an energy of about $30 \times 03 \cdot 10^{-6} \times 10^{6} / 84 \cdot 10^{5}=1.07 \cdot 10^{-6}$ Joule per $\mathrm{m}^{3}$ during 1 pulse, i.e. the mean energy lost during 1 minute is $5.4 \cdot 10^{-7}$ Joule $\mathrm{m}^{-3}$ at an altitude of $100 \mathrm{~km}$.

If we suppose that the energy absorbed by electrons is used solely to cause them to accelerate, then one can estimate the electron energy increase during 1 minute as $2 \cdot 10^{5} \times 10^{6} E_{\mathrm{k}}=3.9 \cdot 10^{-6}$; then, $E_{\mathrm{k}}=2 \cdot 10^{-17}$ Joule/electron, so that $\left(1\right.$ Joule $\left.=6.25 \cdot 10^{18} \mathrm{eV}\right) 125 \mathrm{eV}$ per 1 electron (here $2 \cdot 10^{11}$ is the electron density per $m^{3}$ ) due to 9.8 $M H z \mathrm{HF}$; for HF 3.8 MHz $E_{\mathrm{k}}=16.7 \mathrm{eV}$ during 1 minute.

The case described in the paragraph above will be true if the electron remains in the plasmoid volume during 1 minute. Based on this assumption, we can obtain the upper limit of the accelerated electron energy. So far, we have considered that the plasmoid cools during about 10 minutes; this could be interpreted as meaning that the accelerated electrons could be kept in the volume and continue being heating throughout the 10 minutes, i.e. that they increase their energy by 10 or more times.

An approximate upper limit of the electron energy, then, will be $1.2 \mathrm{KeV}$ for $9.8 \mathrm{MHz}$ and $167 e V$ for $3.8 \mathrm{MHz} \mathrm{HF}$ beams.

If the electron energy distribution $N(W)$ is of Maxwell character, then the part of the distribution of electrons with energy greater than certain $W, N(>W)$ is defined by the expression:

$$
\frac{N(>W)}{N(>0)}=\left(2 \sqrt{\frac{W}{k T}}\right) \cdot \exp \left(\frac{-W}{k T}\right)
$$

Where $\mathrm{kT}$ is a mean electron energy $1.2 \mathrm{KeV}$ and $167 \mathrm{eV}$ for HF 9.8 $\mathrm{MHz}$ and 3.8 $\mathrm{MHz}$ correspondingly and $N(>0)$ $=2 \cdot 10^{5} \mathrm{~cm}^{-3}$ is a density of free electrons at an altitude of $100 \mathrm{~km}$.

At $W=20 \mathrm{KeV}$ and $\mathrm{kT}=1.2 \mathrm{KeV}$ and $167 \mathrm{eV}, N(>W)$ $=2.65 \cdot 10^{-7}$ and $6.5 \cdot 10^{-14}$ respectively. The heated electrons will flow out of the plasmoid along the magnetic field lines according to the Lorentz force:

$$
F=\frac{e}{c}[\vec{v} \times \vec{B}]
$$

Where e, $\vec{v}$, c are the electron charge and velocity and light velocity correspondingly.
The fluxes, $\mathcal{J}\left(>E_{\mathrm{e}}\right)$, formed by this outflow are equal to $J\left(>E_{e}\right)=N(>W) \times v$ where $v$ is electron velocity relative to the earth's surface.

For example, the electron flux with the energy greater than $20 \mathrm{KeV}$ at a mean energy of $1.2 \mathrm{KeV}$ is $\mathcal{J}>20 \mathrm{Ke} V=2.65 \cdot 10^{-7} \times 2 \cdot 10^{5} \times 0.28 \times 3 \cdot 10^{10}=4.5 \cdot 10^{8} \mathrm{~cm}^{2} \mathrm{~s}^{-1}$. Maxwell distribution decreases very sharply to greater than mean values and the flux of $(>40 \mathrm{KeV}$ ) electrons which is about $\approx 6 \cdot 10^{7} \mathrm{~cm}^{-2} \mathrm{~s}^{-1}$ practically could not be registered.

As we noted above, the magnetic field line belonged to the area where the antenna is installed that has shell $L=2.29$. It corresponds to the position of maximum fluxes of the outer radiation belt of electrons.

\section{ELECTRON RESONANCE ACCELERATION}

However, it seems that ionospheric electrons in the powerful HF electromagnetic field do not behave as a neutral gas heated to a certain temperature displaying (generally) Maxwell distribution, even though the cold plasma in the constant magnetic field can show a distribution close to that of Maxwell's.

In the variable electromagnetic field the electrons and ions of the plasma are heated mainly by the resonance interaction with the electric field. Nonrelativistic, cold ionosphere electrons at temperature $T=1000 K$, have a kinetic energy, $E_{\text {kin }}=k T=\left(8.65 \cdot 10^{-5} \mathrm{eV} / T\right) T=0.09 \mathrm{eV}$. Such electrons practically do not participate in gyration around geomagnetic field lines and are unaffected by the geomagnetic field; their gyration radius is equal to $0.0006 \mathrm{~cm}$. When electrons are heated, they begin to gyrate around the magnetic field lines.

The time period of the electron Larmour rotation is $\tau_{\mathrm{g}}=2 \pi R_{\mathrm{L}} / \nu=2 \pi m c^{2} / 300 B c=6 \cdot 10^{-7} s$ (where $R_{\mathrm{L}}$ is the gyration radius) over the antenna and it does not depend on the electron energy when it is nonrelativistic. The gyro frequency $v=1 / \tau_{\mathrm{g}}$ is $1.5 \mathrm{~Hz}$, i.e. it is in the frequency range of the HF antennas $(1-10 \mathrm{MHz})$, and as a result the electrons can be accelerated by the electric fields of the electromagnetic waves emitted by antenna. The electric fields $\mathrm{E}_{0}$ from the $\mathrm{HF}$ radio waves are very large and could be evaluated from the known expression $E_{0} 2 / 8 \pi=W_{\mathrm{d}} / 2$ for the density $\left(W_{\mathrm{d}}\right)$ of electromagnetic field energy.

From relations between electromagnetic values units one obtains: $1 \mathrm{Watt} \mathrm{s} / \mathrm{m}^{3}=1 \mathrm{~V} \times 1$ (coulomb $\left./ \mathrm{s}\right) \times \mathrm{s} / \mathrm{m}^{3}=1 \mathrm{~V} / \mathrm{m}$ x 1 coulomb $/ \mathrm{m}^{2}=36 \pi 10^{9} \mathrm{~V}^{2} / \mathrm{m}^{2}$. 
Then, $E_{0}^{2} / 8 \pi=36 \pi 10^{9} W_{\mathrm{d}} / 2$, in units of $V^{2} / m^{2}$.

At the frequency $3.8 \mathrm{MHz}$ the energy density given off by $\mathrm{HF}$ radiation for 1 second at an altitude of $100 \mathrm{~km}$ is $W_{\mathrm{d}}=5.35 \cdot 10^{-7} / 60=9 \cdot 10^{-9} \mathrm{Ws} / \mathrm{m}^{3}$, and at $9.8 \mathrm{MHz}$ it is $W_{\mathrm{d}}=3.9 \cdot 10^{-6} / 60=6.5 \cdot 10^{-8} \mathrm{Ws} / \mathrm{m}^{3}$, which correspond to the electric fields of $113 \mathrm{~V} / \mathrm{m}$ and $304 \mathrm{~V} / \mathrm{m}$ for 3.8 and 9.8 $\mathrm{MHz}$ respectively. This is a very large electric field compared with, for example, the natural Interplanetary Magnetic Field (IMF) produced by solar wind when it provokes the strongest magnetic storms in the geomagnetosphere, i.e. about $50 \mathrm{mV} / \mathrm{m}$.

If electron gyro frequency at the ionosphere, $1.5 \mathrm{MHz}$, is close to the lowest frequency of the HF antenna $1-2 \mathrm{MHz}$, one can expect that electrons will be accelerated in these large electric fields up to the upper limit energy $2 \pi\left(R_{\mathrm{L}}\right)^{\mathrm{avr}}$ $E_{0}$ for one Larmour rotation when gyro frequency is equal to the antenna frequency and when polarization of the waves is circular, here $\left(R_{\mathrm{L}}\right)^{\text {avr }}$ is averaged gyro radius over one rotation. When a part of the flux of electrons is heated up, for example to a mean of energy of $\sim 16.7 \mathrm{eV}$ and thus has an initial $R_{\mathrm{L}}=25.5 \mathrm{~cm}$, and resonates with the circular HF wave in the phase of maximum wave amplitude, they are accelerated to $\sim 680$ $e V$ for $E_{\text {init }}=16 \mathrm{eV}$.

A differential of energy $\delta E=E_{0} R_{\mathrm{L}} \delta \varphi$; as far as:

$$
R_{L}=\frac{\sqrt{2 m c^{2} E}}{300 B}
$$

then:

$$
\frac{\delta E}{\sqrt{E}}=\frac{E_{0} x \sqrt{2 m c^{2}}}{300 B} \delta \varphi
$$

and the solution is:

$$
\sqrt{E}-\sqrt{E_{\text {init }}}=\frac{\pi E_{0} \sqrt{2 m c^{2}}}{300 B}
$$

The electron energy is increased up to $E_{\mathrm{k}}=670 \mathrm{eV}$ for one Larmour rotation. If the wave has a plane polarization in a horizontal plane (perpendicular to the propagation direction) and a frequency $\left(k \omega_{\mathrm{e}}\right)$ a little different to the electron gyro frequency $\left(\omega_{\mathrm{e}}\right)$, the acceleration of electrons for at least one Larmour rotation period is defined by the expression:

$$
\begin{gathered}
\Delta E=E_{0} R_{L} \omega_{e} \int_{0}^{2 \pi / \omega_{e}} \sin \omega_{e} t \cdot \sin k \omega_{e} t \cdot d t= \\
=E_{0} R_{L} \sin 2 \pi \xi /(2-\xi) \xi
\end{gathered}
$$

Here $\mathrm{E}_{0}$ is the strength of the electric field waves, $R_{\mathrm{L}}$ gyro radius; $0<\xi=1-k<1$. At the limit $\xi \rightarrow 0$, when electron gyro frequency and the radio HF coincide, electron acceleration during one Larmour period is $\Delta E$ $=\pi R_{\mathrm{L}} E_{0}$, different to $\Delta E=2 \pi R_{\mathrm{L}} E_{0}$ for circular polarization, which is more energy efficient. At any $k$ integer, $\Delta E=0$, there is no acceleration.

The necessary time for an electron to leave the plasmoid could be evaluated as $\sim 10^{-4} s$ for a relativistic electron. If the time of gyro rotation is $6 \cdot 10^{-7} \mathrm{~s}$, the electron makes $\sim 10^{2}$ revolutions before leaving the plasmoid volume. It follows from equations (3), (4) that the electron gains $4.8 \mathrm{MeV}$ energy per 100 rotations, and leaves the volume becoming a relativistic electron. If the electromagnetic wave frequency does not coincide with the gyration frequency $f_{\mathrm{g}}$ the energy gain is proportional to the mean wave electric field averaged over the gyration period and in the best case, when $\omega_{\mathrm{HF}} / \omega_{\mathrm{g}}=0.5 k$, where $k=1 ; 3$; $5 \ldots$, it is about $1 / 5$ of the maximum energy gain mentioned above for circular polarization. In this particular case the electrons leave the plasmoid with about $1 \mathrm{MeV}$ relativistic energy.

\section{BOUNCE AND DRIFT MOTION OF HEATED ELECTRONS}

Out flowing electrons fill in the magnetic tube at $L=2.29$ participating in bounce motion along the magnetic field line with the time period of $\tau_{\mathrm{b}}=0.085 L T / \beta$. Here, $T=1.3-0.56 \sin \alpha_{\text {eq }}$, where $\alpha_{\text {eq }}$ is a particle equatorial pitch angle. The plasmoid electrons are produced practically at an altitude of $100 \mathrm{~km}$ from the Earth's surface and $\alpha_{\text {eq }} \sim 2.65^{\circ}\left(\sin \alpha_{\text {eq }}={ }_{\text {eq }} / B_{\text {mirr }}=0.30 / L 30.54=\right.$ $=0.046)$ and $\tau_{\mathrm{b}}=0.108 \mathrm{~L} \beta=0.89 \mathrm{~s}$ for $20 \mathrm{KeV}$ electrons at $L=2.29$. These electrons appear after $\sim 0.5 s$ at the magnetic conjugate point of the same $L$-shell in the northern hemisphere $\left(38.51^{\circ} \mathrm{N} ; 67.33^{\circ} \mathrm{W}\right)$ at an altitude of about $200 \mathrm{~km}$.

This electron flux precipitates into the upper atmosphere over the conjugate point and produces breemstrahlung $\mathrm{X}$-rays radiation (5) in the wide range of the spectrum 0 to $10 \mathrm{KeV}$, and will excite molecules and atoms of the atmosphere creating similar effects to those of the aurora. 
The electrons filling in the magnetic tube, reflecting in the magnetic mirror points of the northern and southern hemispheres, drift eastward with the time period of $\tau_{\delta}=44 / L E \min$, here $E$ in $M e V$, with the drift velocity $\mathrm{v} \delta=0.136 \mathrm{LE}$ degr $/ \mathrm{s}$, that is $0.0062 \mathrm{degr} / \mathrm{s}$ for $20 \mathrm{KeV}$ electrons. During 3 hours of antenna operation $20 \mathrm{KeV}$ electrons filled in a part of a MacIllwain shell spreading approximately to $60^{\circ} \mathrm{W}$ and the fluctuating electron fluxes of $\mathrm{KeV} \sim$ tens $\mathrm{KeV}$ energy could be observed at $L=2.29$, covering a part of the space between geomagnetic latitudes $\approx \lambda=48^{\circ} \mathrm{N}-48^{\circ} \mathrm{S}$ within $11^{\circ} \mathrm{E}$ approximately to $60^{\circ} \mathrm{W}$.

If all ionospheric electrons at the altitude of $100 \mathrm{~km}$ (at the dayside) are accelerated up to quasirelativistic relativistic energies, an expected upward electron flux directed along magnetic field line is $\Phi=0.5 n c \approx$ $10^{5} \times 3 \cdot 10^{10} \approx 10^{14-15} 1 / \mathrm{cm}^{2} \mathrm{~s}$. It is also possible that not all electrons escape simultaneously from the plasmoid and its flowing will continue for 3 hours of antenna operation. Then, flux $\Phi \sim 10^{10-11} 1 / \mathrm{cm}^{2} s$, i.e. it is still very great. The shelter covered by electron fluxes is fine, with a width of about $20 \mathrm{~km}$, which a LEO satellite passes for 3 seconds.

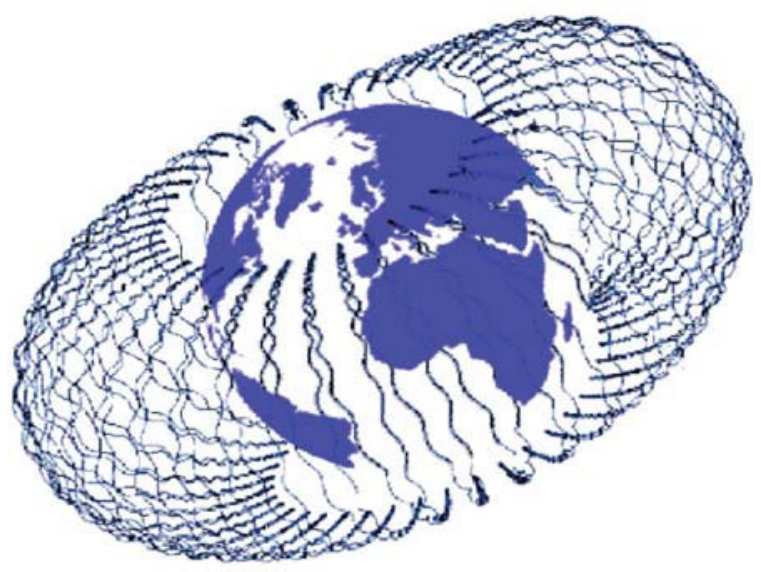

Fig. 2 Shelter formation around the Earth.

\section{CONCLUSION}

This paper has presented rough estimates of fluxes and energy limits of ionospheric electrons artificially accelerated by possible HF radiation. They show that the operating HF antenna can provoke acceleration of the ionosphere electrons up to relativistic energies. The electron flux overwhelming the natural radiation belt flux creates a radiation shelter around the Earth which could be used for various purposes, such as ELF, VLF propagation, better GPS control signals, petroleum research, and space weather information. The main results are the study of cold ionospheric plasma with the interactions of $\mathrm{HF}$ waves at 2.8 and $9.8 \mathrm{MHz}$ emitted at the same time from the ground to space region in order to provoke the plasmoid formation and produce the ionospheric shelter.

\section{ACKNOWLEDGMENTS}

The authors are indebted to the ITA-IEEF for supporting this research and CNPq (Proc. 303511/03-6, Proc. 505756/03-0).

\section{REFERENCES}

[1] J. Emaire, M. Roth, J. Wisemberg, J. I. Vette. "Development of Improved Models of the Earth's Radiation Environment". Institute D'Aeronomie Spatiale de Belgique, Belgique. 1989.

[2] N. G. Basov. "Cosmic Rays in the Stratosphere and in Near Space". Academy of Sciences of the USSR. Moscow, USSR. 1976.

[3] C.E. McIlwain. "Coordinates for Mapping the Distribution of Magnetically Trapped Particles". Journal Geophysical Research. USA. Vol. 66, pp. 3681-3691. 1961.

[4] I. M. Martin, D. B. Rai, J. M. Da Costa, R. Palmeira and N. B. Trivedi. "Enhanced Electron Precipitation in Brazilian Magnetic Anomaly Region”. Nature. England. Vol. 240. Fasc. 100, pp. 84-86. 1973.

[5] I. M. Martin, D. B. Rai, R. A. Palmeira, N. B. Trivedi, J. M. Costa. "Enhanced low-energy gamma-rays at balloon altitudes in Brazilian Magnetic Anomaly region". Nature. England. Vol. 252. Fasc. 5478, pp. 25-27. 1974.

[6] I. M. Martin. "Measurements and calculations of charged particles and X-rays fluxes in stratosphere of Brazilian Magnetic Anomaly region". Master of Science Thesis. ITA. Brazil. 1968. 